\title{
The crude oil fouling of algiers refinery
}

\begin{abstract}
Crude oil fouling in refinery preheat exchangers is a chronic operating problem that compromises energy recovery in these systems. Progress is hindered by the lack of quantitative knowledge of the dynamic effects of fouling on exchanger heat transfer and pressure drop.

In this work, the evolutions of the fouling resistance in the heat exchangers of the crude oil preheat trains of the Algiers refinery is carried out. The results obtained for the two cells of exchangers studies, showed that the fouling resistance increased with time following an exponential evolution in agreement with the model suggested by Kern and seaton, with the existence of fluctuations caused by the instability of the flow rate and the impact between the particles. The bad cleaning $p f$ the heat exchangers involved the absence of the induction period and caused consequently, high values of the fouling resistance in a relatively short period of time.
\end{abstract}

Keywords: heat exchanger, calendar-and-tube, fouling resistance, crude oil, fluid temperature
Volume 2 Issue 4 - 2017

Rima Harche, Abdelkader Mouheb

Department of Chemical Engineering, University of Sciences and

Technology Houari Boumediene, Algeria

Correspondence: Rima Harche, Department of Chemical Engineering, University of Sciences and Technology Houari Boumediene,Algeria, Email s_r_harche@yahoo.fr

Received: September II, 2016 | Published: May 15, 2017

\section{List of symbols}

$\mathrm{R}_{\mathrm{d}}$ : fouling resistance $\left(\mathrm{m}^{2} .{ }^{\circ} \mathrm{C} / \mathrm{kW}\right)$

$\mathrm{U}_{\mathrm{S}}$ : total coefficients of surface heat transfer at the dirty state $(\mathrm{kW} /$ $\left.\mathrm{m}^{2} .{ }^{\circ} \mathrm{C}\right)$.

$\mathrm{U}_{\mathrm{p}}$ : total coefficients of surface heat transfer at the clean state $(\mathrm{kW} /$ $\left.\mathrm{m}^{2} \cdot{ }^{\circ} \mathrm{C}\right)$.

$\mathrm{m}$ : the flow mass of the cold fluid (the crude oil) $\left(\mathrm{m}^{3} / \mathrm{h}\right)$.

$\mathrm{C}_{\mathrm{p}}$ : the heat-storage capacity $\left(\mathrm{kJ} / \mathrm{kg} .{ }^{\circ} \mathrm{C}\right)$,

$\mathrm{t}_{\mathrm{e}}, \mathrm{t}_{\mathrm{s}}$ : output and input temperatures of the crude oil, respectively $\left({ }^{\circ} \mathrm{C}\right)$. $\left({ }^{\circ} \mathrm{C}\right)$.

$\mathrm{T}_{\mathrm{e}}, \mathrm{T}_{\mathrm{s}}$ : output and input temperatures of the ebb of head respectively

$\mathrm{P}_{\mathrm{e}}, \mathrm{P}_{\mathrm{s}}$ : inlet and outlet pressure of the crude oil respectively (bar)

A: the external surface of heat transfer $\left(\mathrm{m}^{2}\right)$.

(F $\Delta \mathrm{Tm})$ : the difference in the logarithmic temperature $\left({ }^{\circ} \mathrm{C}\right)$.

$\mathrm{d}_{4}{ }^{15}$ : density.

$\mathrm{h}_{0}$ : heat transfer coefficient of external film $\left(\mathrm{kW} / \mathrm{m}^{2} .{ }^{\circ} \mathrm{C}\right)$.

$\mathrm{hi}_{0}$ : heat transfer coefficient of internal film brought back to external surface $\left(\mathrm{kW} / \mathrm{m}^{2} .{ }^{\circ} \mathrm{C}\right)$.

\section{Introduction}

One of the serious and complex problems which various industries are facing is the accumulation, on the heat transfer surfaces, of organic compounds or different particles dissolved or present as a suspension in the fluid. This phenomenon, called fouling, affects the operation of the equipments by reducing their thermal effectiveness and by involving a considerable pressure drop. This leads to significant economic losses due to the pumping and the frequent cleaning of the installations.
Crude oil fouling in refinery preheat exchangers is a chronic operating problem that compromises energy recovery in these systems. Progress is hindered by the lack of quantitative knowledge of the dynamic effects of fouling on exchanger heat transfer. ${ }^{1}$ Generally, crude oil flows through the tube side while various other hot streams and pump-around streams flow through the shell side in the heat exchangers. $^{2}$

There is a large variety of deposit problems and installations types prone to fouling. In this study, we present a description of the deposit phenomenon for its modeling. Tools to understand fouling must be developed to provide quantitative information for the validation of the fouling models. Several studies were devoted to the parameters influencing the fouling deposit by chemical reactions. As an example, some studies showed that the rate of fouling increases with a reduction in the fluid temperature. ${ }^{3}$

They explain this by the fact that at constant velocity and temperature, the increase in the thermal transfer involves an increase in fouling. Others observe, on the other hand, an increase in the rate of fouling with the fluid temperature. ${ }^{4,5}$ Radhakrishman et al. ${ }^{6}$ developed a predictive model using statistical methods which can a priori predict the rate of fouling and decrease in heat transfer efficiency of heat exchangers. Aminian \& Shahhosseini ${ }^{7}$ evaluated the artificial neural network (ANN) modeling, for the prediction of crude oil fouling behavior in preheat exchangers of crude oil distillation units. This research showed that the influence of the crude oil velocity and tube diameter of the fouling rate is higher than the tube surface temperature. Mohanty \& Singru $^{8}$ used the C-factor for monitoring of fouling in a calendar-and-tube heat exchanger.

Ishiyama et al. ${ }^{9}$ consider in their work the problem of controlling the disaster inlet temperature by using hot stream bypassing, within a PHT fouling mitigation strategy based on heat exchanger cleaning. Wang et al., ${ }^{10}$ in their results of heat transfer experiments show that the shell-side heat transfer coefficient of the improved heat exchanger increased by $18.2-25.5 \%$, the overall coefficient of heat transfer increased by $15.6-19.7 \%$, and the energy efficiency increased by $12.9-14.1 \%$. Pressure losses increased by $44.6-48.8 \%$ with the solar 
installation. Sanaye \& Hajabdollahi ${ }^{11}$ used a first thermal model which is their NTU method which is applicable for optimal design of a shell and tube heat exchanger.

The fouling of heat exchanges used in refineries is an obstacle to their development. In this study, we will consider the fouling phenomenon of the heat exchanger tubes for the preheat circuit of the Algiers refinery. The heat exchangers cells, E101 CBA and FED, which are used for the heating of the crude oil before its division are exposed to the problem of fouling at the tube side of heat exchangers. In this frame, a study of crude oil deposit on-site is realized which must allow to know its nature and the temporary evolution of the deposit thickness, and the most important point for this studies is to proved the linearization variation between the fouling resistance and the deposit thickness for each the two heat exchanger battery (E101 CBA and FED).

\section{Experimental procedure}

The study was made on the level of three heat exchanger cells of the circuit preheats of the Algiers refinery. The crude oil leaves the vat of storage at room temperature; one of the three centrifugal pumps P101, drives back it towards the atmospheric unit of distillation U101, while crossing the two circuits of the E101 battery E101 CBA and E101 FED, which is the tube-calendars type with a floating head.

The crude crosses the battery with dimensions tube where it is heated using the backward flow head that is a mixture of light products, coming from the top of the fractionating column C101 on the level of the plate N46. Oil passes them by the electrostatic disaster by the addition of treated water and caustic soda. Treated water is injected at the entry of the E101 exchanger and the entry of the disaster, with an aim of the crude oil washing and of involved with it salts present there. Each cell is made up of three heat exchangers, laid out in a series Figure 1.

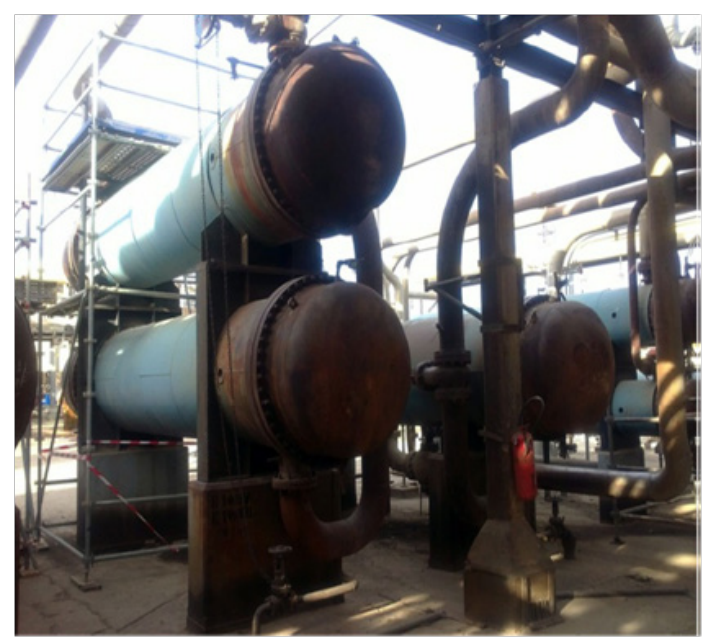

Figure I Picture of the EIOI CBA heat exchanger.

The characteristics of these exchangers are presented in the Table below Table 1.

Our experimental study is based on the following assumptions.

i. The same crude oil flow crosses the tube side for each exchanger. ii. The same backward flow crosses the calendars side for each exchanger.

iii. The number of total tubes is the sum of the each heat exchanger tube.

iv. The total number of tube side master keys is equal to three times of the number of tube side master keys for each heat exchanger.

v. The output and input temperatures of the two fluids are taken at the ends of the cell.

Table I Characteristics of the heat exchangers cells

\begin{tabular}{|c|c|c|}
\hline \multirow[t]{2}{*}{ Characteristics } & \multicolumn{2}{|c|}{ E IOI CBA FED } \\
\hline & $\begin{array}{l}\text { Calandres } \\
\text { side }\end{array}$ & $\begin{array}{l}\text { Tubes } \\
\text { sides }\end{array}$ \\
\hline Fluid circulating & Ebb of head & Crude \\
\hline Flow mass (lb/h) & $1,000,000.00$ & Oil \\
\hline Density API & 76 & 44.4 \\
\hline Viscosity (cS) & - & $2.40-0.96$ \\
\hline \multicolumn{3}{|l|}{ Input/output } \\
\hline Input temperature $(\mathrm{F})$ & 240 & 80 \\
\hline Output temperature (F) & 150 & 220 \\
\hline A number of master keys & I & 4 \\
\hline Fouling factor of & 0.001 & 0.002 \\
\hline DP acceptable (bars) & - & 5 \\
\hline Material of construction & \multicolumn{2}{|l|}{ Carbon steel } \\
\hline Calendar diameter (in.) & \multicolumn{2}{|l|}{42} \\
\hline Distance between chicanes (in.) & \multicolumn{2}{|l|}{18} \\
\hline Number of calendars & \multicolumn{2}{|l|}{6} \\
\hline External diameter of tubes (in.) & \multicolumn{2}{|l|}{0.75} \\
\hline Thickness of tubes & \multicolumn{2}{|l|}{ BWG I4 } \\
\hline Length of tubes (in.) & \multicolumn{2}{|l|}{20} \\
\hline Total number of tubes & \multicolumn{2}{|l|}{$6,600.00$} \\
\hline The step: opposite square(in.) & \multicolumn{2}{|l|}{ I } \\
\hline Total surface of heat exchange ( $\mathrm{ft} 2)$ & \multicolumn{2}{|l|}{$25,000.00$} \\
\hline $\begin{array}{l}\text { Global coefficient of heat Exchange } \\
\text { in the clean state }\left(\text { Btu/h ft } 2 \_ \text {F) }\right.\end{array}$ & \multicolumn{2}{|l|}{63.5} \\
\hline
\end{tabular}

\section{Calculation method}

This experimental study was carried out during one 05 months. The method that we used to follow the fouling evolution consists in carrying out a heat balance at the boundaries of the battery E $101 \mathrm{CBA}$ and $\mathrm{E} 101$ FED by the intermediary of measurements of the output and input temperatures, and the heat and cold fluids flow Figure 2. The latter were taken each two hours during all the day.

This method, though indirect, makes it possible to detect with which moment it is necessary to stop the installation for cleaning. 


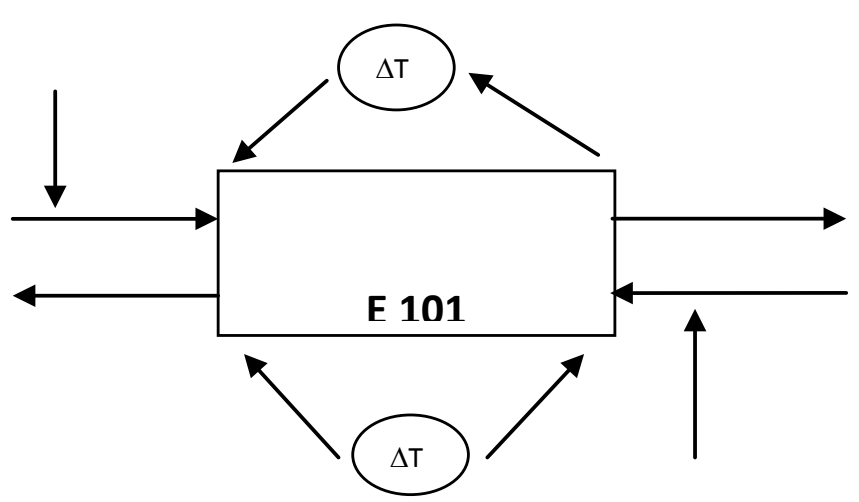

Figure 2 The measurement method at the boundaries of the EIOI battery.

In the present study, the temporal evolution of the crude oil fouling resistance was studied by considering each cell consisting of three exchangers in series. Taking into account that it is not possible to measure all temperatures, we considered the three exchangers as a single one. As noticed, only one exchanger with three master keys and 12 master keys with a tube for each cell E101 CBA and FED.

The calculation of the fouling resistance was made by using the following relation:

$$
R_{d}=\left(\frac{1}{U_{s}}\right)-\left(\frac{1}{U_{p}}\right)
$$

$\mathrm{U}_{\mathrm{S}}$ and $\mathrm{U}_{\mathrm{p}}$ are the total of heat transfer surface coefficients of the dirty state and the clean state, respectively. The total of heat transfer surface coefficients of the dirty state was given in the time course, via the expression:

$$
U s=\frac{m \cdot C_{p} \cdot\left(t_{s}-t_{e}\right)}{A \cdot F \cdot \Delta T m}
$$

Where $m$ is the flow mass of the cold fluid (the crude oil), $C_{p}$ is the heat-storage capacity, $\mathrm{t}_{\mathrm{e}}$ and $\mathrm{t}_{\mathrm{s}}$ are the output and input temperatures, respectively, A the external surface of heat transfer (F DTm) the difference in the logarithmic temperature; and $U_{S}$ is the total of heat transfer coefficients brought back to external surface.

This relation is drawn from the assessment of energy on the heat exchanger by supposing the isolated system and the physical properties of the two fluids, as well as, the heat transfer coefficients remain constant along the exchanger.

\section{Calculation of $U_{p}$}

In the Algiers refinery, the operating conditions at the boundaries of the E101 exchanger are variable, it is necessary to revalue the total of heat exchange coefficients in the proper conditions $U_{p}$ corresponding to the new operating conditions:

$$
U_{p}=h_{0} h_{i 0} /\left(h_{0}+h_{i 0}\right)
$$

\section{With:}

$\mathrm{h}_{0}$ : The heat transfer coefficient of external film.

$\mathrm{h}_{\mathrm{i} 0}$ : The heat transfer coefficient of internal film brought back to the external surface.

\section{Results and discussion}

The evolution of the fouling resistance in the series heat exchangers of the circuit preheats of Algiers refinery was followed for a study period quoted previously. These series were already in service for 660 days before the beginning of the present study.

Nevertheless, it was proceeded has an emergency shutdown in lasted five days then its discount in service. This stop is due to a reduction in load because of a flight at the level of the pipe, and also for the cleaning of one of the heat exchangers of the E $101 \mathrm{CBA}$ battery.

All the results for the fouling resistance for both series are presented in the form of curves on Figure 3, Figure 4.

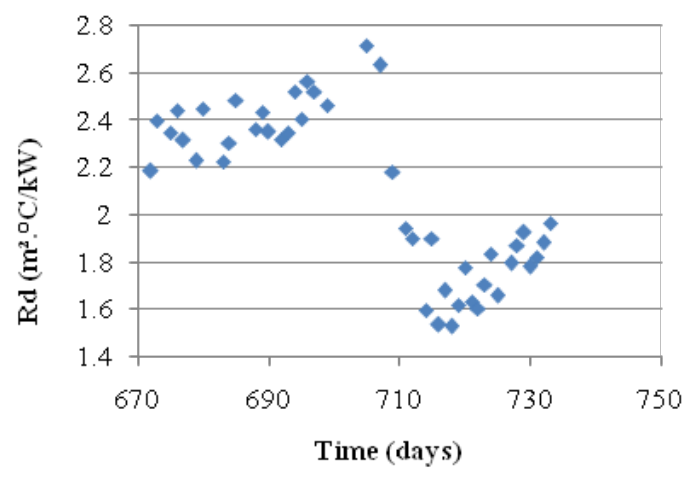

Figure 3 Temporal evolution of the fouling resistance for the E I0I CBA series.

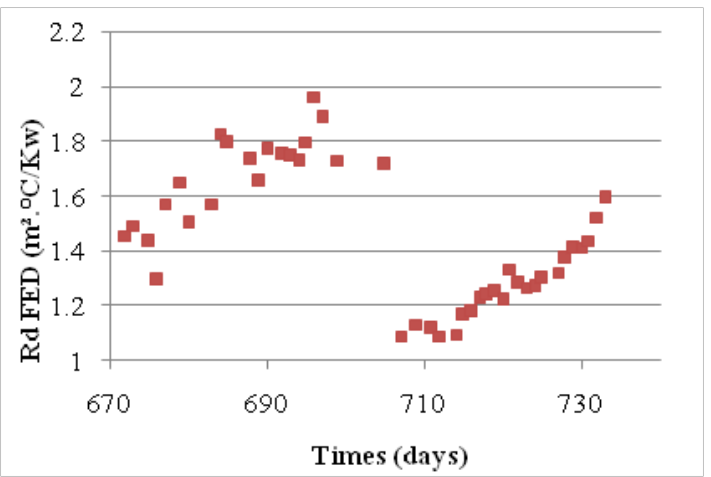

Figure 4 Temporal evolution of the fouling resistance for the E IOI FED series.

According to the values of these resistances, which are the majority higher than zero, these series present a state of fouling. This is obvious since, as mentioned before, these exchangers were in service since more than one year, and according to the studies carried out on the same series by Dr. Oufer in the year $2000,{ }^{13}$ fouling starts with appraiser after approximately 160 days of its startup.

The curves presented show that the temporal evolution of the fouling resistance, seems to follow an asymptotic evolution which conforms to the model of Kern and Seaton,,$^{14}$ with the absence of the induction period. That can be explained by the delay recorded between the last cleaning which corresponds to $t=0$, and the beginning of experiments. As it appears clearly as the fouling resistance represents increases with the time until reaching a maximum value about $2,7 \mathrm{~m}^{2}$ ${ }^{\circ} \mathrm{C} / \mathrm{kW}$ for the battery E $101 \mathrm{CBA}$ and about $2 \mathrm{~m}^{2 \circ} \mathrm{C} / \mathrm{kW}$ for the serie 
E $101 \mathrm{EDF}$; this in the first part of the curve which varies at the time from 670 to 705 days, beyond, one observes a reduction in the fouling resistance, compared to the first part of study. It attack the value of 1,9 $\mathrm{m}^{2}{ }^{\circ} \mathrm{C} / \mathrm{kW}$ for the battery E101 CBA and about $1,6 \mathrm{~m}^{2}{ }^{\circ} \mathrm{C} / \mathrm{kW}$ for the cell E $101 \mathrm{EDF}$

The reduction of the fouling resistance in the two curves of Figure 3 , Figure 4 is due to the need for a stop emergency for one exchanger of the series E101 CBA, and of the same with the variations of the operating conditions in the Algiers refinery, which are:

a. Increase in the flow which is twice higher than that of the last year, from where increase the fluid speed (crude oil).

b. The good quality of the crude oil: a very low content salts and sediments.

c. The washing water of the crude oil is well water treated and does not pose a problem of tartar and corrosion.

The maximum values of the fouling resistance represent an asymptotic resistance, since the series functioned since more than one year, a sufficient period so that the resistance asymptotic value is reached. The fluctuations observed on these curves are due with the variation of flow which, while acting on the shear stress to the wall, causes réentrainement particles of the deposit or their deposition according to the sent flow value.

In the same way, according to the curve of Figure 5, it appears clearly which the fouling resistance is higher in battery E 101 CBA than in battery E $101 \mathrm{EDF}$; and this is right because of the position of the one batteries compared to the other (the first battery undergoes a higher flow of cured oil and the more fouling).

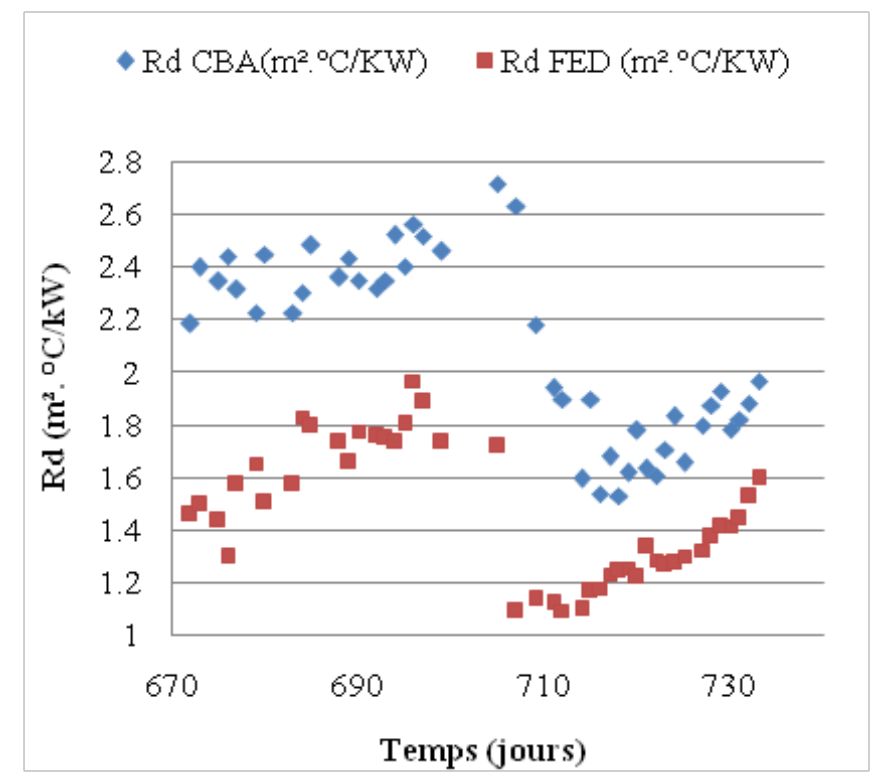

Figure $\mathbf{5}$ Temporal evolution of the fouling resistance for the two series of exchangers [12].

Nevertheless, the curves giving the variation of the fouling resistance according to the average temperature of the crude oil illustrated on Figure 6, Figure 7 for the cells E101 CBA and E101 EDF, respectively show that the fouling resistance of the two cells grows when the crude oil temperature increases.

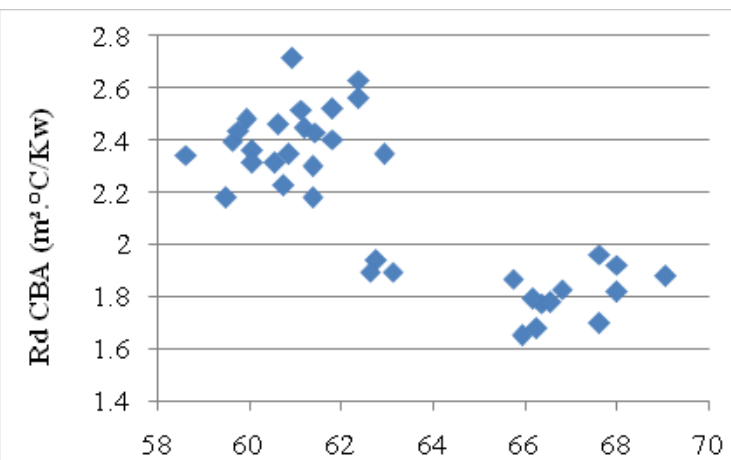

The aver age temperature of the crude oil $\left({ }^{\circ} \mathrm{C}\right)$

Figure 6 Influence of the crude oil temperature on the fouling resistance for the $\mathrm{E}$ IOI CBA serie.

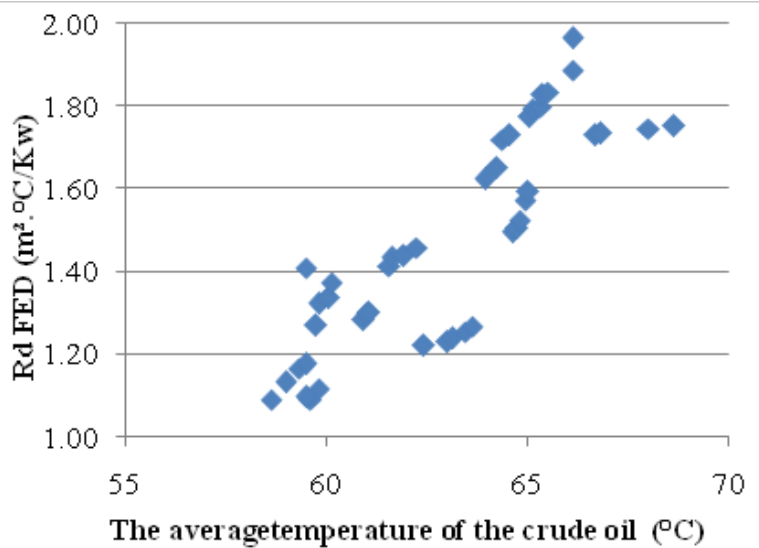

Figure 7 Influence of the crude oil temperature on the fouling resistance for the E IOI FED

\section{Conclusion}

The present study allows a better understanding, from a viewpoint of a thermo energy, of the fouling effect in the tubular heat exchangers of the preheat circuit of Algiers refinery. The study concerned the battery E101CBA and FED allowed deposit analysis, the determination of both time-dependent fouling resistance and deposit thickness and the variation of deposit thickness according to fouling resistance. The results obtained revealed an exponential evolution of the fouling resistance, in conformity with the model of Kern and Seaton with the absence of the induction period, which is explained by the consequence of a bad cleaning, or a gap between the present study and the beginning of the functioning of the heat exchangers after the last stop. We had a more important increase of the fouling resistance in the first battery E101 CBA than in the second battery E101 FED. This is obviously because the crude oil flow is higher in the first battery compared to the second battery and the same one ensured the increase in the fouling resistance with the increase in the crude oil temperature.

\section{Acknowledgements}

None.

\section{Conflict of interest}

The author declares no conflict of interest. 


\section{References}

1. Yeap B, Wilson Di, Polley GT, et al. Mitigation of crude oil refinery heat exchanger fouling through retrofits based on thermo-hydraulic fouling models. Chemical Engineering Research and Design. 2004;82(1):53-71.

2. Radhakrishnan, Ramasamy M, Zabiri H, et al. Heat exchanger fouling model and preventive maintenance scheduling tool. Applied Thermal Engineering. 2007;27:2791-2802.

3. Srinivasan M. Heat exchanger fouling of some Canadian crude oils. Heat Transf Eng. 2005;26:7-14.

4. Asomaning S. Heat exchanger fouling by petroleum asphaltenes. University of British Columbia, Columbia, 2005.

5. Saleh Z, Sheikholeslami R, Pwatkinson A. Fouling characteristics of a light Australian crude oil. Heat Transf Eng. 2005;26(1):15-22.

6. Radhakrishman VR, Ramasamy M. Heat exchanger fouling model and preventive maintenance scheduling tool. Applied Thermal engineering. 2005;27:2791-2802.

7. Aminiam J, Shahhosseini S. Evaluation of ANN modeling for prediction of crude oil fouling behavior. Applied Thermal engineering. 2008;28:668-674.
8. Mohanty DK, Singru PM. Use of C-factor for monitoring of fouling in a shell and tube heat exchanger. Applied Thermal engineering. 2001;36(5):2899-2904.

9. Ishiyama EM, Heins AV, Paterson WR, et al. Scheduling cleaning in a crude oil preheats train subject to fouling: incorporating desalter control. Applied Thermal engineering. 2010;30(13):1852-1862.

10. Wang S, Wen J, Yanzhong L. An experimental investigation of heat transfer enhancement for a shell-and-tube heat exchanger. Applied Thermal engineering. 2009;29(11):2433-2438.

11. Sanaye S, Hajabdollahi H. Multi-objective optimization of shell and tube heat exchangers. Applied Thermal engineering. 2010;30:1937-1945.

12. Harche R, Absi R, Mouheb A. Study of the fouling deposit in the heat exchangers of Algiers refinery. Int J Ind Chem. 2014;5:1-8.

13. Oufer L, Mouheb A, Kaci O, et al. Fouling of a shell and tube preheat in Refinery plant. International congress of chemistry and production, Praha. Czech Rep. 2000.

14. Butterworth D. Design of shell and tube heat exchangers when the fouling depends on local temperature and velocity. Applied Thermal engineering. 2002;22(7):789-801. 